\title{
A saúde indígena no processo de implantação dos Distritos Sanitários: temas críticos e propostas para um diálogo interdisciplinar
}

\author{
Indigenous peoples' health and the implementation \\ of Health Districts in Brazil: critical issues \\ and proposals for a transdisciplinary dialogue
}

Renato Athias 1,2

Marina Machado 2

\footnotetext{
1 Programa de Pós-Graduação em Antropologia, Centro de Filosofia e Ciências Humanas, Universidade Federal de Pernambuco. Rua Prof. Moraes Rego s/no, 13 o andar, Recife, $P E$ 50670-901, Brasil. zarabata@elogica.com.br 2 Associação Saúde Sem Limites.

C. P. 31, São Gabriel da Cachoeira, AM 69670-000, Brasil. <http://www.ocara.org.br/ssl> sslim@originet.com.br
}

\begin{abstract}
Based on the authors' experience, this paper discusses a series of problems during the implementation of so-called Indigenous Health Districts (DSEI) in Brazil, related to organization of health services provision as viewed by both health professionals and anthropologists. The authors report on the Health District model's underlying concepts and present the different approaches used to implement the DSEI. The authors' experience refers to the Rio Negro area - in the northwestern Amazon, representing 10\% of Brazil's total indigenous population - and the Brazilian Northeast, specifically the State of Pernambuco, with an indigenous population estimated at 20,000.
\end{abstract}

Key words Local Health Systems; Health Services; South American Indians

Resumo A proposta do presente trabalho é a de expor, a partir das experiências dos autores, alguns problemas que se apresentam no atual processo de implantação dos distritos sanitários indígenas, relacionados à organização dos serviços de saúde segundo o entendimento de profissionais de saúde e de antropólogos. Para tal, os autores reportam-se aos conceitos fundamentais inerentes ao modelo de Distrito Sanitário, explicitam-nos e, por fim, apresentam as abordagens que estão sendo usadas comumente no processo de distritalização para as populações indígenas. As experiências vivenciadas pelos autores referem-se à região do Alto Rio Negro - no noroeste amazônico, representando uma realidade de 10\% do total da população indígena do Brasil - e à região Nordeste - mais especificamente, o Estado de Pernambuco - com população indígena estimada em 20.000 indivíduos.

Palavras-chave Sistemas Locais de Saúde; Serviços de Saúde; Índios Sul-Americanos 


\section{Introdução}

O atual modelo de organização dos serviços de saúde para as áreas indígenas, na concepção de Distritos Sanitários, nasceu no âmbito das Conferências Nacionais de Saúde, no início da década de noventa, no bojo do movimento da Reforma Sanitária. Porém, somente na II Conferência Nacional de Saúde para os Povos Indígenas (II CNSPI), ocorrida em 1993, este modelo foi referendado pelo movimento indígena e por profissionais de saúde que atuam com estas populações. A proposta versava a respeito da implantação de um modelo de saúde adequado às áreas indígenas, inserido em um subsistema de atenção à saúde ligado ao Sistema Único de Saúde (SUS). A partir daí, a concepção e o modelo de Distrito Sanitário Especial Indígena (DSEI) passou a ser reivindicação permanente na pauta do movimento indígena organizado, bem como dos profissionais de saúde das áreas indígenas.

A decisão política de implantar o modelo assistencial referendado pela II Conferência foi tomada pela Fundação Nacional de Saúde (FUNASA) ao final de 1998, obedecendo, em linhas gerais, a proposta da II CNSPI no que se refere à participação social na elaboração das políticas de saúde. No entanto, apresenta algumas distorções quanto ao aspecto de autonomia orçamentária e financeira dos DSEIs. O modelo administrativo adotado pela FUNASA contém duas vertentes. Na primeira, as Coordenações Regionais da FUNASA atuam como ordenadoras de despesas e, por conseguinte, controlam os recursos financeiros destinados aos Distritos; na segunda modalidade administrativa, o nível central da FUNASA realiza a celebração de convênios com organizações indígenas, Organizações Não-Governamentais (ONGs), Secretarias de Saúde e universidades para a execução das ações de saúde nas áreas indígenas. Sendo assim, para que haja, de fato, uma organização dos serviços de saúde que possibilite o atendimento das demandas atuais e promova uma postura mais próxima às propostas referendadas na II Conferência, torna-se necessária a discussão do modelo administrativos preconizados neste momento pela FUNASA.

Os Distritos que estão sendo implantados em todo o Brasil contemplam as características peculiares de cada área indígena e estão sendo concebidos dentro de um processo de discussão que envolve vários atores sociais, tais como: as organizações indígenas, os profissionais de saúde, as ONGs, as universidades e órgãos federais como a FUNASA e a Fundação Nacional do Índio (FUNAI). De um lado, esta plurali- dade é importante e necessária, pois reflete as características de cada área. No entanto, dadas as diversas formas de contato das populações indígenas com a sociedade envolvente e, em conseqüência, os diferentes estágios de organização política frente a esta mesma sociedade, o processo de distritalização nas áreas indígenas tende a desenvolver-se de forma variada de região para outra. Em determinadas regiões, como a Amazônia, onde a organização política das populações indígenas tem histórico mais longo, a possibilidade de participação no controle social das ações de saúde torna-se mais viável. Em outras regiões, como no Nordeste e Centro-Oeste e também no Sul do país, o exercício do controle social em saúde deverá ser estimulado pelas instituições que estarão responsáveis pela execução dos serviços de saúde e pela implantação e funcionamento regular dos Conselhos Distritais de Saúde com a participação efetiva dos índios. Apesar de toda essa diversificação e das dificuldades pertinentes a todo o processo de democratização e de inclusão social, existe o vislumbre de serem gerados modelos sanitários que atendam às necessidades básicas e estratégicas das comunidades indígenas no Brasil, desde que seja mantida a linha política de distritalização da saúde indígena.

Grande parte dos antropólogos que estão trabalhando nas áreas indígenas tiveram ou têm ligações com a questão da saúde indígena. A saúde é tema central em muitas regiões em virtude da situação precária, em termos de acesso aos serviços de saúde, a que a maioria dos povos indígenas do Brasil estão submetidos. Pode-se notar que, nos últimos 30 anos, vários projetos de saúde foram iniciados nas áreas indígenas - em especial, por organizações não-governamentais - com apoio de recursos provindos da cooperação internacional. Os resultados advindos destes projetos constituem-se em acervo significativo de experiências em saúde indígena. Neste trabalho, não iremos analisar essas experiências e sim referilas no contexto desse processo de distritalização. Isso implica ressaltar que há um saber antropológico construído a partir de práticas sanitárias em áreas indígenas com mais de 30 anos de existência. As experiências efetuadas pelo Serviço de Proteção ao Índio (SPI) / FUNAI também merecem ser sistematizadas, pois há mais de 50 anos que a agência oficial mantém projetos de saúde em áreas indígenas. Este saber deve ser sistematizado ou classificado nas diversas abordagens em saúde indígena, a fim de ressaltar as experiências que deram resultados significativos e divulgá-las tanto aos prestadores de serviços quanto aos formuladores 
de políticas de saúde, no sentido de colaborar com o trabalho dos mesmos, assim como no de contribuir para a melhoria das condições de vida e de saúde dos povos indígenas.

O presente trabalho propõe apresentar, a partir das experiências dos autores, alguns problemas que se apresentam neste processo de implantação dos distritos sanitários indígenas segundo o entendimento dos profissionais de saúde e de antropólogos relacionados à organização dos serviços de saúde. Preferimos a designação Distrito Sanitários Indígena, sem a qualificação de Especial, pois o termo Indígena já indica que é específico. Para tal, os autores reportam-se aos conceitos fundamentais inerentes ao modelo de distrito, explicitam-nos e, por fim, expõem as abordagens que estão sendo usadas comumente nesse processo de distritalização. As experiências concretas vivenciadas pelos autores referem-se à região do Alto Rio Negro - no noroeste amazônico, representando uma realidade de $10 \%$ do total da população indígena do Brasil - e à Região Nordeste - mais especificamente, o Estado de Pernambuco - com população indígena estimada em 20.000 indivíduos.

\section{Distritos Sanitários}

Os Distritos Sanitários foram implantados no Brasil a partir de 1987 (Mendes, 1995) e existe literatura significativa acerca dessas experiências no âmbito da saúde pública. As primeiras iniciativas remontam ao processo de distritalização apoiado pela Organização Pan-americana de Saúde (OPAS) / Organização Mundial de Saúde (OMS), que canalizavam a implantação de distritos em municípios considerados estratégicos. Os primeiros municípios a iniciar essa forma de organização de serviços foram Salvador, Curitiba e São Paulo. Tais experiências estavam relacionadas à idéia de Distrito Sanitário como processo social de mudanças das práticas sanitárias e remetem a número significativo de discussões e avaliações realizadas por sanitaristas e especialistas em saúde pública. Vale lembrar que essas experiências encontram respaldo importante na cooperação internacional italiana no sentido de documentação e divulgação das mesmas.

Neste trabalho estamos trabalhando com a noção de Distrito Sanitário que é reconhecido como "unidade operacional e administrativa mínima do sistema de saúde, definida com critérios geográficos, populacionais, epidemiológicos, administrativos e políticos, onde se localizam recursos de saúde públicos e privados, or- ganizados com a participação da sociedade organizada para desenvolver ações de saúde capazes de resolver a maior quantidade possíveis de problemas de saúde" (Capote, 1988:18).

Portanto, a noção de Distrito Sanitário indígena está centrada na organização da prestação de serviços de saúde pertinentes a cada realidade étnica, de forma que as ações decorrentes sejam eficazes para determinada população indígena, sendo fundamental a participação das diversas instâncias organizativas indígenas na formulação das políticas do setor. As experiências deveriam apontar os problemas no nível organizativo, cuja resolução deveria ser encontrada no local.

Os distritos sanitários, na qualidade de processos sociais de mudança das práticas sanitárias, não são entendidos como tal pela maioria dos profissionais de saúde que atuam no âmbito da saúde pública e, tampouco, pelos administradores de sistemas locais de saúde, dando lugar a duas estratégicas bem identificadas por Mendes (1995). O autor assinala que, no âmbito dos processos de implantação dos distritos sanitários, observam-se duas práticas recorrentes. Uma, que identifica como "topográficaburocrática”, a qual reduz as atividades de organização dos serviços de saúde no âmbito de território específico sem se desvencilhar dos vícios existentes na prática administrativa. Ou seja, não rompe com o paradigma assistencial; apenas criam-se novos espaços burocráticos sem mudar de fato as formas de prestação de serviços e, por conseqüência, o distrito não vai além de uma reforma administrativa. A outra estratégia referida pelo autor é a que identifica o distrito como "processo social", procurando atuar no âmbito das mudanças na prestação de serviços e na inclusão de práticas sanitárias de modo a obter impacto na situação de saúde da população.

Como foi citado anteriormente, a saúde indígena não tem avaliação mais global, até o presente, sobre as diferentes formas existentes das práticas. Os diversos projetos de saúde implantados na áreas indígenas não chegaram a formular consenso mínimo de como os serviços de saúde seriam melhor organizados, tendo em vista sua relação ou não com um modelo nacional que também optou por favorecer os sistemas locais de saúde. Em outras palavras, ainda não há reflexão mais ampla no tocante a como organizar um subsistema de saúde indígena relacionado com o SUS.

O SUS oferece, como concepção geral, a possibilidade de criação de sistemas de saúde baseados na realidade local, o que favoreceria a diversidade de modelos. No âmbito da saúde 
indígena, o que se observou nestes últimos anos foi uma divisão dos serviços entre a FUNAI e a FUNASA: a primeira, com atividades eminentemente curativas e a segunda, com atividades de prevenção. Em se tratando de modelos de saúde e sob a perspectiva de comando único de ações, essa dicotomia mostrou-se inviável e incoerente, criando relações paternalistas para determinadas populações indígenas e gerando a impossibilidade de execução de serviços de saúde de maneira integral.

\section{Distrito Sanitário Indígena do Rio Negro}

A elaboração da proposta de organização dos serviços de saúde para a região do Alto Rio Negro foi fruto de intenso trabalho de articulação interinstitucional, que se vem consolidando desde 1997, a partir da II Conferência de Municipal de Saúde, e contou com a participação de representantes indígenas e dos profissionais de saúde ligados ao setor de toda a região, de políticos locais, inclusive com as Forças Armadas, que têm representação bem expressiva na área.

A região do Alto Rio Negro possui características bastante peculiares quanto aos povos indígenas que ali habitam - tais como a extensão territorial e as dificuldades de acesso às comunidades indígenas -, apresentando-se como grande desafio à elaboração de uma proposta de Distrito Sanitário adequada a esse território (Oliveira et al., 1997). O Município de São Gabriel da Cachoeira, sede distrital, conta com $108.000 \mathrm{~km}^{2}$ de extensão, e é entrecortado pelos rios formadores da Bacia do Rio Negro, em que há diversos trechos encachoeirados, motivo pelo qual, muitas vezes, para passar de uma a outra comunidade torna-se necessário que os profissionais de saúde e os comunitários façam um trecho a pé, transportando todos os equipamentos necessários ao trabalho de saúde. Pensar na operacionalização desses serviços com vistas à melhoria no acesso aos serviços de saúde para as populações que residem nessa região exige esforço técnico de modo a adequar as rotinas de trabalho sem perda de qualidade.

A articulação interinstitucional constituída revela a maturidade das organizações e entidades de saúde que atuam na região, uma vez que nenhuma delas tem capacidade operacional para dar conta das 600 comunidades indígenas existentes. A sustentabilidade do modelo assistencial para esta realidade depende do trabalho mais intenso na formação de agentes indígenas de saúde e de outros recursos humanos locais.
A participação indígena nesse processo de elaboração consolida o espaço que as organizações indígenas conquistaram ao longo dos anos. Existem, na região, cerca de 28 associações indígenas, filiadas à Federação das Organizações Indígenas do Rio Negro (FOIRN), que as congrega desde 1986. O trabalho da FOIRN está direcionado à defesa dos direitos indígenas quanto à demarcação de terras, educação e saúde. As Terras Indígenas do Rio Negro foram demarcadas em 1998, após processo de luta de 20 anos. Semelhante acúmulo de experiência em termos de participação social capacitou o movimento indígena no Rio Negro a expressar suas demandas no momento da concepção do modelo assistencial e a participar das fases de execução e avaliação das atividades.

\section{Distrito Sanitário Indígena em Pernambuco}

Vivem no Estado de Pernambuco cerca de 20.000 índios, distribuídos em oito diferentes etnias, que habitam a região do Agreste e do Sertão; contudo, a maioria das terras indígenas não foi demarcada e ainda está em processo de identificação. As ações de saúde eram realizadas sem a preocupação de desenvolver uma reflexão em torno da especificidade de uma organização dos serviços de saúde apropriada a essas populações e estiveram, até então, sob a responsabilidade da FUNAI e dos municípios onde as aldeias indígenas estão localizadas. A prática dessas ações de saúde seguiam o modelo assistencialista, efetuada pela FUNAI e, nos períodos eleitorais, pelos municípios. Não existem registros de trabalho de ONGs com populações indígenas em Pernambuco.

As organizações indígenas em Pernambuco priorizam, em toda a sua mobilização, a questão da demarcação de suas terras e, conseqüentemente, a da afirmação da identidade étnica. A problemática da saúde vem em segundo plano, sob a forma de reivindicações específicas e pontuais. Neste contexto, a implantação do Distrito Sanitário Indígena ocorreu de forma verticalizada, e o movimento indígena não dispôs do tempo necessário para entender a proposta como um todo e discuti-la adequadamente. Houve uma única reunião promovida pela FUNASA em abril de 1999, da qual participaram as lideranças indígenas, em que se tratou basicamente da definição do território distrital. Em seguida deu-se início ao processo de implementação da proposta em ritmo acelerado, sem a participação indígena em seu acompanhamento e desenvolvimento. A equipe da 
FUNASA do nível local não elaborou uma prática de diálogo com os usuários dos serviços, o que tem provocado reflexos importantes no processo de implantação do distrito.

As articulações do Distrito estão sendo feitas diretamente com os municípios que vão incorporar a execução de ações de saúde nas áreas indígenas através de convênios específicos, que prevêem a contratação de equipes multidisciplinares para a prestação de serviços de saúde naquelas localidades. Cabe ressaltar que o Ministério da Saúde (MS)/FUNASA está investindo uma série de incentivos financeiros nos municípios - procurando seguir os parâmetros adotados na Norma Operacional Básica do SUS/96 -, para que sejam estimulados a executar a Atenção Básica nas comunidades indígenas. Desta forma, as equipes de saúde para o distrito estão sendo escolhidas e contratadas pela prefeitura local, o que pode envolver um jogo de interesses políticos às portas de ano eleitoral, sem considerar necessariamente a melhoria do acesso aos serviços de saúde. Em outras palavras, a organização dos serviços de saúde nessa região está sendo feita sem discussão mais ampla com a população indígena, afora que a inserção desse subsistema de saúde no SUS aponta para distorções históricas da saúde pública no país, apropriadas ao uso político-eleitoral da questão.

\section{Discursos e práticas}

A partir das duas experiências narradas resumidamente, torna-se possível verificar os caminhos pelos quais o processo de distritalização da saúde indígena pode passar, bem com explicitar que este não foge da realidade dos processo de luta pelo estado de bem-estar social no país.

Em se tratando do tema pertinente a este trabalho, pode-se também localizar elementos com os quais é possível elaborar um arcabouço de informações importantes para profissionais de saúde e antropólogos, com vista ao melhor entendimento das possibilidades do desenvolvimento de sistemas locais de saúde democráticos e culturalmente sensíveis. Abrindo essa discussão em aspecto mais amplo, elencaremos espaços e temas de conhecimento nas quais os autores percebem a existência de convergência, divergência e complementaridade nos discursos de antropólogos e profissionais de saúde, visando uma prática adequada quanto à atenção à saúde dos povos indígenas e esclarecendo que esses discursos não estão generalizados entre estes profissionais.
Seria interessante iniciar essa discussão pela análise da noção de participação. A participação, enquanto tema relativo ao desenvolvimento social, mereceu atenção em literatura vasta e, em particular, quando se trata de participação em saúde, os registros são bastante expressivos no Brasil. A formação dos profissionais de saúde no país está voltada prioritariamente para a intervenção e atendimento individual da demanda espontânea, pautado pela ética profissional, o que os responsabiliza pela luta na preservação da vida. Muitas vezes, isso dificulta a percepção mais ampla da necessidade de participação do grupo social nos aspectos inerentes à atenção a saúde. Neste sentido, existe uma prática de organização de serviços de saúde que relega a segundo plano a participação social, perdendo-se assim a oportunidade de diálogo, por exemplo, entre a prática médica ocidental e a medicina tradicional, a qual pode contribuir para o desenvolvimento de um sistema local de saúde adequado à realidade dos povos indígenas. Os antropólogos - cuja formação está voltada ao conhecimento mais aprofundado de determinado grupo populacional - poderiam estabelecer tal ligação, buscando instrumentos de facilitação dessa discussão para que o diálogo seja efetivado.

Outra área de conhecimento que consideramos central neste processo de implantação dos distritos é a de planejamento e organização dos serviços de saúde. Neste aspecto encontramos diferentes abordagens, pois a noção de organização dos serviços de saúde, para que seja eficiente e eficaz, demandaria informações básicas sobre as populações indígenas no tocante a suas concepções de doença e saúde, essenciais para estabelecer um processo de planejamento que contemple as necessidades básicas e estratégicas do grupo indígena em que se está atuando. A dificuldade torna-se maior, pois os profissionais de saúde não são tão flexíveis em aceitar “outros" modelos, que fogem àqueles já preconizados de assistência de saúde. Essa dificuldade é resultado de uma lacuna em seu processo de formação acadêmica pela não inclusão de disciplinas relativas às Ciências Sociais e à Antropologia da Saúde nos currículos. A concepção de saúde e doença existente entre os povos indígenas interfere no modelo de assistência já preconizado, e os profissionais de saúde, pela falta de conhecimento mais aprofundado dessas concepções, encontram dificuldade em adaptar tais modelos, provocando assim dificuldades na organização dos serviços de saúde.

Esses modelos organizados no conhecimento epidemiólogico concentram as seguintes etapas: 1) as doenças que mais ocorrem na 
área; 2)o que afeta a população; 3) soluções de problemas de saúde; e 4) acompanhamento e avaliação. A maior flexibilidade neste aspecto proporcionaria abertura mais ampla para a compreensão e identificação clara dos problemas de saúde, surgindo, em decorrência disso, um modelo de atendimento mais adequado à realidade indígena local.

Essas concepções diferenciadas encontram-se centradas na idéia de acesso aos serviços de saúde, com diferentes abordagens entre antropólogos, profissionais de saúde e, também, entre os grupos indígenas. As diferentes noções de acesso aos serviços de saúde são provenientes da falta de clareza e compreensão mais ampla dos diversos problemas de saúde identificados. Esses problemas são referidos de diversas formas sem discussão mais ampla, o que entendemos necessário antes mesmo de iniciar qualquer tipo de planejamento em saúde. E neste caso, por exemplo, uma simples febre pode-se tornar uma grande complicação em uma área indígena. Em outras palavras, o nível de complexidade não é o mesmo e a gravidade da situação será referida sob diversas formas aos prestadores de serviços de saúde.

Assim, os dados antropológicos relativos aos grupos indígenas deveriam ser melhor explicitados, de forma a garantir adequada compreensão dos problemas por parte dos profissionais de saúde. Por sua vez, os antropólogos não dispõem de conhecimento mais específico no que se refere à organização de serviços de saúde e ao potencial criativo de sistemas locais de saúde que poderiam vir a ser construídos mediante a incorporação das diversas concepções do processo saúde/doença existentes entre os grupos indígenas. Já existe literatura expressiva sobre essas concepções (Athias, 1998; Buchillet, 1992, 1997) que mereceriam maior atenção. Neste aspecto, pode-se verificar que o discurso antropológico busca fortalecer a medicina tradicional sem, no entanto, haver uma abordagem de complementaridade com o sistema médico ocidental. Na Colômbia, onde habitam também as mesmas etnias existentes no Rio Negro, tivemos notícias que, por um período, o "pajé" indígena teve inserção oficial no sistema de saúde local, demonstrando a possibilidade de efetivar uma real valorização dos conhecimentos médicos tradicionais. Conhecer essas experiências torna-se necessário e nossa vivência leva-nos a refletir sobre a noção de acesso à saúde que incorpore os sistemas médicos tradicionais à organização das referências dos serviços.

As duas experiências de distritalização relatadas anteriormente mostram a diversidade $\mathrm{e}$ o potencial existente com relação ao território de um distrito. No entanto, a questão de definição de um território distrital tem sido um dos elementos mais conflitantes no processo de distritalização nas áreas indígenas. Essa discussão merece debate mais amplo com possibilidades bastante inovadoras, uma vez que permite o desenvolvimento de sistemas locais de saúde que tomem em conta as bases geopolíticas e os sistemas médicos dos grupos indígenas. Um território distrital, em nossa concepção, vai além de uma base física relacionada ao solo, constituindo uma extensão definida em termos de organização social dos grupos indígenas, portanto, um território econômico, político, cultural e, sobretudo, epidemiológico. Em virtude da incompreensão de uma geopolítica indígena e da falta de conhecimento mais aprofundado acerca da epidemiologia, a discussão dos territórios distritais torna-se ainda mais importante no sentido de garantir serviços eficientes de saúde. E, neste aspecto, as lógicas de entendimento tanto de profissionais de saúde quanto de antropólogos não entram em acordo. Os primeiros, centralizam seus discursos na organização dos serviços de forma bastante operacional, em detrimento de procurar desenvolver sistemas locais que pudessem contemplar outros elementos, como, por exemplo, os mecanismos locais da medicina indígena, os quais enriqueceriam o modelo local a ser proposto. Os antropólogos, por sua vez, têm dificuldade de explicitar com maior clareza todos os conhecimentos relativos a uma "geopolítica" indígena, que conformaria a melhor compreensão das ações de saúde em território específico. No âmbito mais amplo dos discursos entre antropólogos podemos identificar convergência quando se trata da questão do território e que poderia ser complementada com informações mais precisas. A dificuldade está na falta de espaços de discussões sobre essa questão que abordem o tema da organização dos serviços de saúde como elemento aglutinador dos diversos conhecimentos.

O que se observa, por exemplo, no processo de distritalização em Pernambuco, é um entendimento por parte dos profissionais de saúde, de conformar o território do distrito de acordo com os limites municipais. Neste tipo de prática, as prefeituras locais receberão parcela maior de recursos para atuar na área indígena, mas verifica-se historicamente que essas prefeituras não executam os serviços de saúde planejados, pois estão presas a práticas clientelistas ligadas ao voto eleitoral. Neste sentido, o processo de distritalização em Pernambuco não aponta à melhoria dos serviços de saúde 
para as populações indígenas, que não têm espaço para discutir essas práticas - o diálogo é inexistente - uma vez que a relação com as prefeituras locais não ocorrem de modo pacífico.

Por último, outra área de conhecimento em que é possível existir divergência de entendimento está relacionada ao sistema de informação, sobretudo na discussão da elaboração de instrumentos que contemplem informações pertinentes para subsidiar o planejamento das ações e na vigilância em saúde. Neste aspecto observa-se a necessidade, durante a elaboração ou adaptação desses instrumentos, de haver maior complementaridade entre os conhecimentos dos antropólogos e dos profissionais de saúde, criando subsídios para que o sistema de informação em saúde para os distritos sanitários indígenas seja concebido sob uma óptica de praticidade e de flexibilidade que leve em consideração a diversidade cultural das populações indígenas. Esses sistemas deveriam ser responsáveis pelo gerenciamento do distrito de forma integrada aos diversos sistemas de informação já adotados no nível nacional. Julgamos necessário uma avaliação crítica desses sistemas para poder compreender a lógica de funcionamento que os direciona. Neste sentido, os antropólogos enfatizam a necessidade de criar um sistema de informação que contemple as especificidades étnicas de cada grupo indígena. Na realidade existe, por parte dos antropólogos, desconhecimento dos sistemas de informação já existentes tanto na sua prática quanto na relação com o SUS. E essa falta de conhecimento abre a possibilidade de divergências, sobretudo ao se tratar da 'integração' ao sistema nacional de informação em saúde, havendo a necessidade de estudar as possíveis adaptações no sistema de informação existente.

A seguir, elencamos pontos básicos que podem orientar a discussão relativa aos sistemas de informação em saúde indígena, ainda necessária para melhor garantir a implantação dos distritos sanitários indígenas. Um sistema de informação deveria ser capaz de:

- identificar efetivamente os problemas e os recursos para gerenciamento local;

- registrar as especificidades e melhorar a discriminação das informações produzidas em campo;

- envolver a população local e os profissionais do distrito na coleta de informações;

- $\quad$ ser prático na coleta de informações;

- fornecer dados precisos para melhor gerenciamento e que alimentem o sistema nacional de informação em saúde.

Para finalizar, gostaríamos de voltar ao tema da participação, que está intimamente vinculado à mudança da prática sanitária que se pretende efetuar na saúde indígena. Acreditamos que o envolvimento da população indígena seja de extrema importância para direcionar as práticas de saúde nos distritos sanitários indígenas. Insistimos que a condução do processo de distritalização implica a identificação clara de todos os aspectos culturais que envolvem o território distrital e exige contínua avaliação a cada passo do processo.

A prática sanitária desenvolvida até então nas áreas indígenas tem sido pontual e individualizada, enfrentando problemas em níveis locais sem referência mais ampla. Poderíamos designar essa prática como imediatista e centrada na demanda espontânea. O que se pretende com os distritos sanitários indígenas é justamente mudar essa prática e, para tanto, deverá haver maior participação indígena no âmbito do entendimento do Distrito Sanitário como processo social. Neste caso, a prática sanitária é vista como enfrentamento contínuo dos problemas previamente discutidos, de modo que a vigilância à saúde torne-se um imperativo.

\section{Referências}

ATHIAS, R., 1998. Doença e cura - Sistemas médicos e representação entre os Hupdë-Maku da região do Rio Negro, Amazonas. Horizontes Antropológicos, 9:237-260.

BUCHILLET, D., 1992. Os povos Tukano e a questão da saúde. Amazonas em Tempo, Manaus, 29 jan. Caderno Cultura, p. 8.

BUCHILLET, D., 1997. Tuberculose, busca de assistência médica e observância terapêutica na Amazônia brasileira. França - Flash Saúde, 11.

CAPOTE, R., 1988. O Processo de organização e a regionalização dos serviços. In: Sistemas Locais de
Saúde (Secretaria Estadual de Saúde, org.), pp. 17-26, São Paulo: Instituto da Saúde, Secretaria Estadual de Saúde.

MENDES, E. V., 1995. Distrito Sanitário - O Processo Social de Mudança das Práticas Sanitárias do SUS. São Paulo: Editora Hucitec/Rio de Janeiro: ABRASCO.

OLIVEIRA, N.; MACHADO, M.; ARGENTINO, S. \& ATHIAS, R., 1997. Considerações sobre a Saúde das Populações Indígenas do Rio Negro. São Paulo: Associação Saúde Sem Limites. (mimeo.) 